\title{
Erratum to: SAGES video classics
}

\section{Michael Brunt}

Published online: 3 October 2013

(C) Springer Science+Business Media New York 2013

\section{Erratum to: Surg Endosc}

\section{DOI 10.1007/s00464-013-3131-0}

The Electronic Supplementary Material (ESM) accompanying this article was inadvertently omitted. The link is hereby restored.

The online version of the original article can be found under doi:10.1007/s00464-013-3131-0.

Electronic supplementary material The online version of this article (doi:10.1007/s00464-013-3234-7) contains supplementary material, which is available to authorized users.

L. M. Brunt ( $\square)$

Department of Surgery, Washington University, St Louis,

MO, USA

e-mail: bruntm@wustl.edu 